
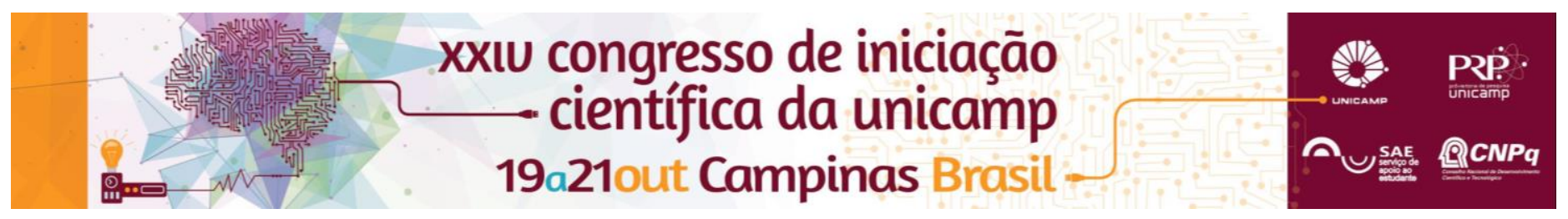

\title{
Avaliação da ação da ferramenta de redução de artefato metálico em diferentes regiões de um FOV
}

\author{
Thaís D. J. Paz *, Polyane M. Queiroz, Deborah Q. Freitas
}

\section{Resumo}

O objetivo do presente estudo foi avaliar se a ferramenta de redução de artefato age de forma homogênea em todo o FOV. Um phantom cilíndrico de cera utilidade foi confeccionado com uma amostra cilíndrica de metal em seu interior. Foram adquiridas imagens tomográficas na presença e ausência da ferramenta, com o phantom na posição central e anterior do FOV. Os valores de desvio-padrão de uma área controle e área ao redor da amostra de metal (área teste) foram usados para quantificar o ruído na imagem tomográfica. Os dados foram submetidos a análise estatística pelo Teste t Student, com nível de significância de 0,05 . Na presença da ferramenta, observou-se diferença significante em relação ao posicionamento, tanto para a área controle $(p=0,0012)$ quanto para a área da amostra $(p=0,03)$, sendo observados menores valores quando a ferramenta estava presente. Imagens de melhor qualidade são obtidas quando os objetos escaneados estão centralizados no FOV.

Palavras-chave: tomografia por raios $X$, artefatos, redução de artafato.

\section{Introdução}

Diferentes tamanhos de campo de visão (field of view FOV) podem ser utilizados para a aquisição da imagem tomográfica e o objeto pode assumir diferentes posicionamentos em um FOV. A ferramenta de redução de artefato busca melhor qualidade da imagem. O presente estudo foi proposto com o objetivo de avaliar se a ferramenta de redução de artefato age de forma homogênea em diferentes regiões do FOV. Foi confeccionado um phantom de cera utilidade com uma amostra metálica cilíndrica em seu interior. Foram adquiridas imagens tomográficas do phantom na presença e ausência da ferramenta, com o phantom em posição anterior e central no FOV. Foram obtidos valores de desvio-padrão de uma área controle e uma área teste; esses valores foram usados para quantificar o ruído da imagem.

\section{Resultados e Discussão}
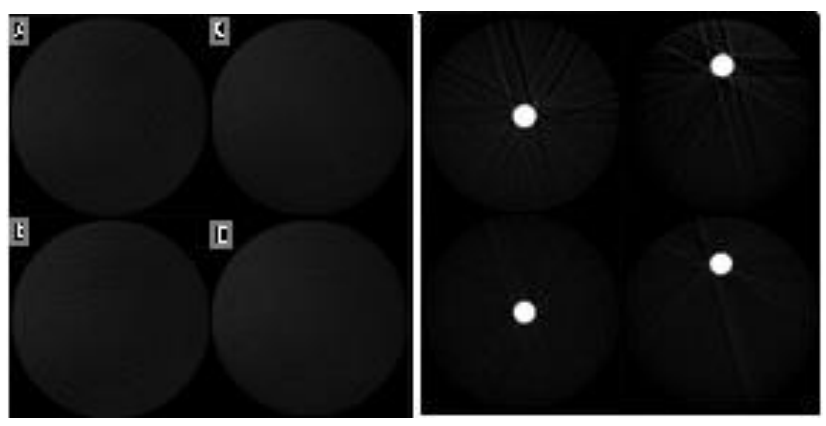

Figura 1. Área controle. Figura 2. Área teste.

$\begin{array}{lllllcll}\text { (A) Centro } & \text { e } & \text { SF; } & \text { (A) } & \text { Centro } & \text { e } & \text { SF; } \\ \text { (B) Anterior } & \text { e } & \text { SF; } & \text { (B) } & \text { Anterior } & \text { e } & \text { SF; } \\ \text { (C) Centro } & \text { e } & \text { CF; } & \text { (C) } & \text { Centro } & \text { e } & \text { CF; } \\ \text { (D) } & \text { Anterior } & \text { e } & \text { CF. } & \text { (D) } & \text { Anterior } & \text { e } & \text { CF. }\end{array}$

${ }^{*} \mathrm{SF}=\mathrm{Sem}$ ferramenta. ${ }^{*} \mathrm{CF}=\mathrm{Com}$ ferramenta.
$\mathrm{Na}$ Tabela 1, é possível observar que houve diferença significante $(p=0,0012)$ em relação ao posicionamento, para a área controle, quando a ferramenta estava presente.

Tabela 1. Quantificação do ruído na área controle.

\begin{tabular}{ccc} 
& Sem ferramenta & Com ferramenta \\
\hline Central & $25,8 \pm 2,27$ & $24.47 \pm 1,29$ \\
Anterior & $25,7 \pm 1,48$ & $26,30 \pm 1,94$ \\
$p$ - valor & 0,98 & 0,0012 \\
\hline
\end{tabular}

$\mathrm{Na}$ Tabela 2, é possível observar que houve diferença significante $(p=0,03)$ na presença da ferramenta, para a área teste.

Tabela 2. Quantificação do ruído na área teste.

\begin{tabular}{ccc}
\hline & Sem ferramenta & Com ferramenta \\
\hline Central & $250,01 \pm 150,05$ & $160.90 \pm 310,60$ \\
Anterior & $334.98 \pm 152.90$ & $447,16 \pm 610,22$ \\
$\mathrm{p}$ - valor & 0,18 & 0,03 \\
\hline Independente da área, há menor quantidade de ruído \\
quando o phantom está centralizado no FOV.
\end{tabular}

\section{Conclusões}

A ação da ferramenta é influenciada pelo posicionamento do objeto no FOV. Imagens de melhor qualidade são obtidas quando os objetos escaneados estão centralizados no FOV

\section{Agradecimentos \\ À CNPq pelo apoio financeiro.}

\footnotetext{
Bechara, B., Moore, W.S., McMahan, C.A. et al. Metal artefact reduction with cone beam CT: an in vitro study.Dentomaxillofac Radiol. 2012; 41:248-25

Taylor, C. Evaluation of the effects of positioning and configuration on contrastto-noise ratio in the quality control of a 3D Accuitomo 170 dental CBCT system. Dentomaxillofac Radiol. 2016;45(5):20150430.

Taylor, C. Evaluation of the effects of positioning and configuration on contrastto-noise ratio in the quality control of a 3D Accuitomo 170 dental CBCT system Dentomaxillofac Radiol. 2016;45(5):20150430.
} 